\title{
Valgus deformiteli dizde total diz protezi
}

\author{
Total knee arthroplasty in valgus knee deformity
}

\author{
Ali Yüce ${ }^{1}$, Yunus İmren² \\ ${ }^{1}$ Başakşehir Çam ve Sakura Şehir Hastanesi, Ortopedi ve Travmatoloji Ana Bilim Dalı, Başakşehir, İstanbul \\ ${ }^{2}$ Prof. Dr. Cemil Taşçıoğlu Şehir Hastanesi, Ortopedi ve Travmatoloji Ana Bilim Dalı, Şişli, İstanbul
}

Total diz protezi (TDP) uygulanan hastaların \%10-15'inde çeşitli derecelerde valgus deformitesi görülmektedir. İleri evre valgusu olan dizler tüm valgus deformitelerinin \%5'ini oluşturur. Bu dizlerde nedenler; hipoplastik lateral kondil, lateral tibial platoda kemik kaybı, tibianın dış rotasyon deformitesi, femoral ve tibial metafiziyel valgus açılanması ve patellar dizilim bozukluğu gibi kemik anormallikleri ile iliotibial bant, lateral kollateral bağ, posterolateral kapsül, arka çapraz bağ ve popliteus tendonu gibi lateral yumuşak dokuların kontraktürünün bir kombinasyonudur. Kemik ve yumuşak doku anormallikleri bu hastalarda TDP cerrahisini zorlu hale getirmektedir. Hem kemik hem de yumuşak doku problemleri için kombine cerrahi prosedürler tercih edilmelidir. Cerrahide amaç, yeterli yumuşak doku dengesine ve nötral mekanik aksa (eksene) sahip, stabil ve fonksiyonel alt ekstremite elde etmektir. Tedavide ilk aşama altta yatan patolojilerin tespiti için ameliyat öncesi klinik ve radyolojik değerlendirmedir. Lateral yumuşak doku gevşetme prosedürleri, medial kollateral bağ gerginliğinin ayarlanması, kemik kesileri ve kısıtlı/menteşeli implant uygulamalarının bir ya da birkaçının kombinasyonu uygulanabilir. Her hasta için standart bir gevşetme prosedürü uygulamak yerine dizin durumuna göre aşamalı gevşetme önerilmektedir. Cerrahın tecrübesi, ameliyat öncesi değerlendirme, eldeki implant seçenekleri ve dizin stabilitesi dikkate alınarak cerrahi tedaviyi planlamak esas olmalıdır.

Anahtar sözcükler: valgus diz; gonartroz; diz protezi; deformite
There are various degrees of valgus deformity in $10-15 \%$ of patients who have undergone total knee arthroplasty (TKA). Knees with severe valgus deformity constitute $5 \%$ of all knee valgus deformities. These are caused by bony abnormalities such as hypoplastic lateral condyle, bone loss in the lateral tibial plateau, external rotation deformity of the tibia, femoral and tibial metaphyseal valgus angulation, and patellar malalignment or soft tissue contractures such as iliotibial band, lateral collateral ligament, posterolateral capsule, posterior cruciate ligament, and popliteus tendon or a combination of both. The presence of both bony and soft tissue abnormalities make TKA surgery challenging in these patients. Combined surgical treatments should be preferred in order to correct soft tissue and bone abnormalities together. The aim of surgery is to obtain a stable and functional lower extremity with adequate soft tissue balance and neutral mechanical axis. The first step in treatment is preoperative clinical and radiological evaluation to detect underlying pathologies. Lateral soft tissue release procedures, adjustment of medial collateral ligament tension, bony cuts and constrained/hinged implant selection can be applied either in combination or individually. Sequential soft tissue release is recommended according to the condition of the valgus knee, instead of applying a standard release procedure. Planning for surgery should be essential in considering the surgeon's experience, preoperative clinical and radiological evaluation, available implant options, and knee stability.

Key words: valgus knee; gonarthrosis; knee prosthesis; deformity
B ilimsel ve endüstriyel ilerleme ile artan nüfus ve ortalama yaşa paralel olarak yaşam kalitesi standartlarının gelişimi, total diz protezini (TDP), ortopedi ve travmatoloji alanında en sık yapılan cerrahi işlemlerden biri haline getirmiştir. ${ }^{[1]}$ Koronal planda tibiofemoral açının $10^{\circ}$ 'den fazla olması dizin valgus deformitesi olarak tanımlanır (Şekil 1) ve tüm primer TDP olgularının \%10-15'inde valgus deformitesi mevcuttur. ${ }^{[2]}$ ileri derecede valgus deformitesi ise, ayakta ön-arka radyografilerde eklemde $>20^{\circ}$ valgus dizilimi şeklinde tanımlanmakta olup, tüm artrozlu valgus dizlerin yalnızca \%5'ini oluşturmaktadır. ${ }^{[3]}$ Travma sonrası artrit, romatoid artrit, raşitizm ve renal osteodistrofi gibi hastalık ve durumlar valgus dizine yol açabilse de, primer osteoartrit valgus deformitesinin en yaygın nedenidir. ${ }^{[4]}$ ileri evre valgus deformitelerinde; medial kapsüler bağ kompleksinin yetersizliği, belirgin lateral yumuşak doku kontraktürü ile lateral femoral kondilde ve/veya lateral tibial platoda belirgin kemik defekti mevcuttur. ${ }^{[3,5]}$ Valgus diz deformitesindeki bu

İletişim / Contact: Doç. Dr. Yunus İmren • E-posta / E-mail: yunusimren@gmail.com

ORCID iD: Ali Yüce, 0000-0003-3751-6644 • Yunus İmren, 0000-0002-8056-6156

Geliş / Received: 7 Temmuz 2021 • Kabul / Accepted: 17 Ağustos 2021 


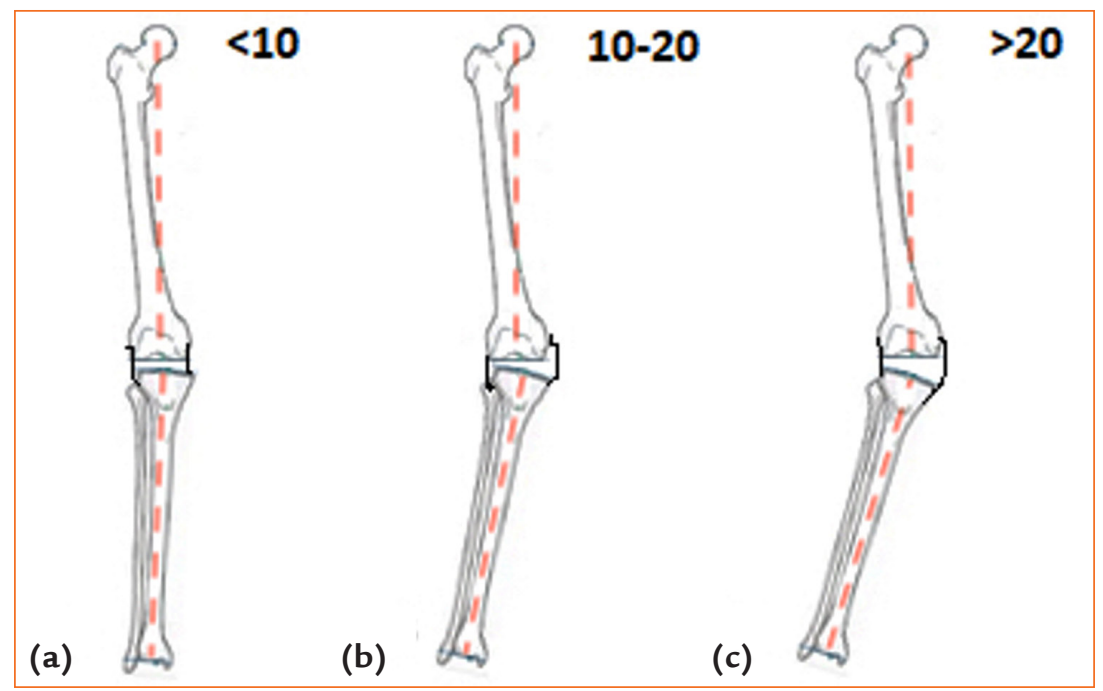

Şekil 1. a-c. Tibiofemoral mekanik aks açısının (TFA) $10^{\circ}$ 'nin altında olduğu normal erişkin diz (a). TFA'nın $10^{\circ}-20^{\circ}$ arasında olduğu valgus diz (b). İleri derecede valgus deformitesi; TFA $>20^{\circ}$ (c).

kemik ve yumuşak doku anormalliklerinin kombinasyonu TDP'yi karmaşık hale getirmektedir. ${ }^{[6]}$

Medial destek yapılarının serbestleştirilmesinin genellikle öngörülebilir şekilde gerçekleştirilebildiği bir varus deformiteli dizden farklı olarak, valgus dizde lateral yapıların gevşetilme sırası halen tartışmalı ve sonuçları daha az tahmin edilebilirdir. ${ }^{[5,7]}$ Lateral yapıların yetersiz gevşetilmesi rezidüel (kalıcı) deformiteye yol açabilirken; aşırı gevşetilmesi ise ameliyat sonrası mediolateral instabiliteye ve dolayısıyla kısıtlı implantların zorunlu kullanımına neden olabilir. ${ }^{[3,5]}$ Kısıtlı implantların kullanımının, kısa ve orta vadeli takiplerde çok iyi sonuçlara sahip olmasına rağmen, kemik-implant ara yüzünde artan stres nedeniyle protez gevşemesi olasılığı dâhil olmak üzere uzun dönem sonuçları yüz güldürücü değildir. ${ }^{[5]}$ illeri derecede bir valgus dizde TDP yapılırken alt ekstremite mekanik aksının (ekseninin) restorasyonu ve doğru bağ dengesi, protezin stabilitesi, uzun süreli sağkalımı ve iyi fonksiyonel sonuç için önemli faktörlerdir. ${ }^{[4]}$

\section{PATOANATOMI}

Valgus artritik diz sıklıkla hipoplastik lateral kondil, lateral tibial platoda kemik kaybı, tibianın dış rotasyon deformitesi, femoral ve tibial metafiziyel valgus açılanması ve patellar dizilim bozukluğu ile karakterize karmaşık bir deformitedir. ${ }^{[4,8,9]}$ Ayrıca iliotibial bant (iTB), dış yan bağ (DYB), posterolateral kapsül (PLK), arka çapraz bağ (AÇB) ve popliteus tendonu (POP) gibi lateral yumuşak doku yapılarının kontraktürü ile eşlik eden instabilite bulunabilir. ${ }^{[4,6,8]}$ Nadiren gastroknemiusun lateral başı (GLB) ve biseps femorisin uzun başı da etkilenir. ${ }^{[10]}$ Lateral yumuşak dokuların kontraktürü, iç yan bağın (IYB) gevşekliği ile ilişkili olabilir ve ileri deformiteli olgularda bu karmaşık tabloya IYB yetmezliği de eklenebilir. ${ }^{[4,7]}$

\section{Sınıflandırma}

Eklemdeki açısal deformitenin ciddiyeti ve yumuşak doku tutulumunun derecesi temel alınarak valgus diz için birçok sınıflandırma tanımlanmıştır. ${ }^{[4]}$ En sık kullanılan Krackow sınıflandırması, medial yumuşak doku bütünlügü ve önceki cerrahileri esas alarak üç tip valgus diz tanımlar. ${ }^{[11,12]}$ Tip 1'de, lateralde yumuşak doku kontraktürüyle birlikte lateral kompartmanda kemik kaybına ikincil valgus deformitesi gözlenir ve medialde yumuşak dokular korunmuştur. Tip 2'de ek olarak medial kapsüler bağ kompleksinde belirgin zayıflık mevcuttur. Tip 3 ise, aşırı düzeltilmiş proksimal tibial osteotomi sonrası proksimal tibia eklem çizgisinde ciddi valgus varlığı şeklinde tanımlanır. Görece karmaşık bir artroplasti gerektiren valgus dizine odaklanan bu sınıflandırma, ileri valgus dizin tedavisine yönelik kavramların henüz net olarak tanımlanmadığı bir zamanda ana hatlarılya belirtilmiştir. Daha hafif valgus deformitelerini içermemesi ve cerrahın ameliyat sırasında olası teknik zorlukları öngörmesine veya uygun implantı seçmesine tam anlamıyla yardımcı olamaması, bu sınıflamanın dezavantajları arasında yer almaktadır. ${ }^{[12]}$ Ranawat farklı olarak, lateral kompartmandaki yumuşak dokuların gerginliği ve deformitenin sabit veya düzeltilebilir oluşunu dikkate alarak valgus deformitesini üç evre olarak tanımlamıştır (Şekil 2). ${ }^{[13]}$ Evre l'de valgus deviasyonu 


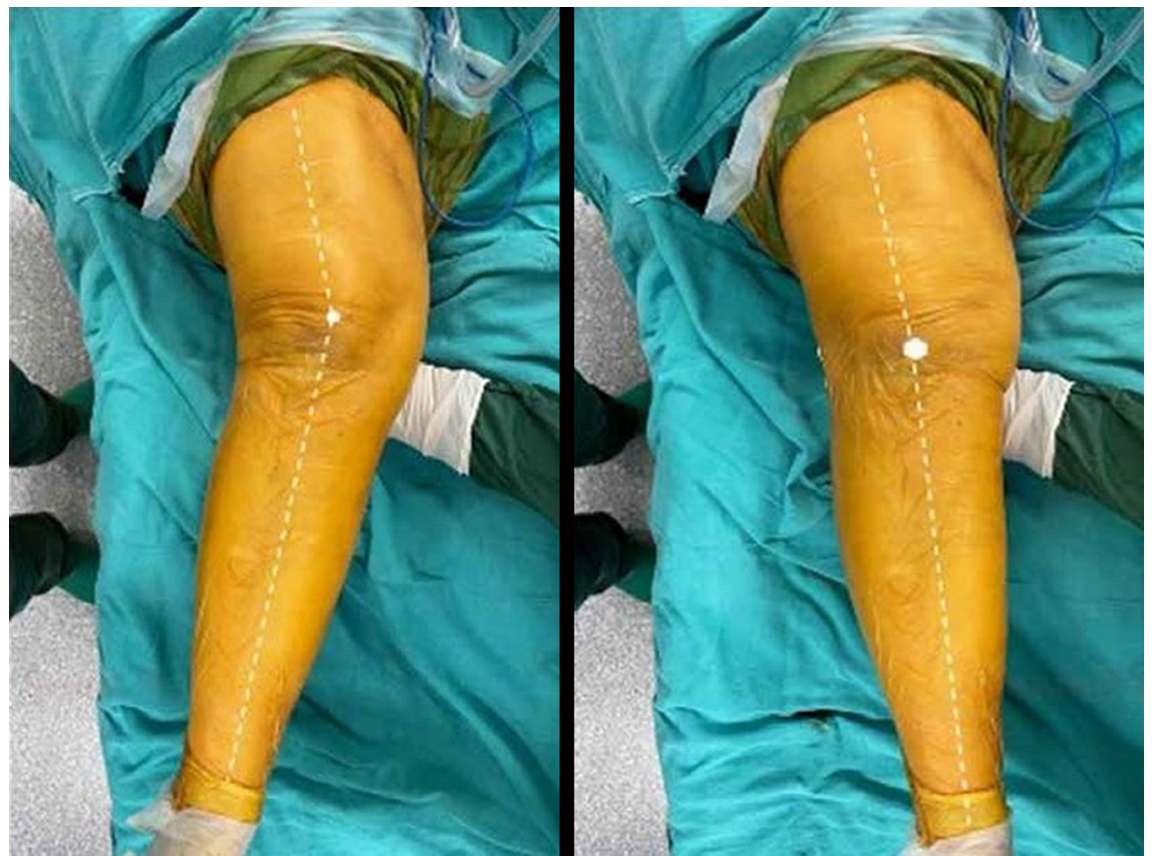

Şekil 2. Varus-valgus stres testleri ile sağ dizdeki deformitenin sabit veya düzeltilebilir oluşunun değerlendirilmesi.

$10^{\circ}$ 'den azdır, deformite varus stres testi ile düzeltilebilir ve IYB fonksiyonel ve sağlamdır. Bu tip, tüm valgus dizlerinin \%80'ini oluşturur. Evre II'de (valgus dizlerinin $\% 15^{\prime} \mathrm{i}$ ), deformite $10^{\circ}$ ile $20^{\circ}$ arasında değişir ve IYB fonksiyonel olarak gevşektir. Valgus dizlerinin kalan \%5'ini oluşturan evre III, medial stabilize edici elemanlarda ciddi yetmezlik ile birlikte $20^{\circ}$ 'den yüksek bir kemiksel deformiteyi tanımlar. ${ }^{[13]}$

\section{Ameliyat öncesi Klinik ve Radyolojik Değerlendirme}

Valgus dize yönelik TDP için de ameliyat öncesi planlama mutlaka yapılmalıdır. Ameliyat öncesi muayenede diz ekleminin stabilitesi ve kemik kaybı, eklem hareket açıklığı (EHA), fleksiyon kontraktürü, bağların yeterliliği ile diz deformitesinin tipi ve derecesi değerlendirilir. ${ }^{[4,12]}$ Cerrah, ileri valgus deformiteli hastaları olası peroneal sinir araz hakkında bilgilendirmelidir. ${ }^{[4]}$

Kollateral bağların yeterliliği; varus ve valgus stres testleri, ayakta yük vererek çekilmiş ortoröntgenogram, yük vererek çekilmiş ön-arka ve yan radyografilerle ve Merchant grafisi ile değerlendirilmeli; deformitenin şiddeti belirlenmelidir (Şekil 3 ve 4). ${ }^{[4,12]}$

Radyografiler kemik deformitesi, patellar kalınlık ve pozisyon, alt ekstremite dizilimi, medial-lateral açıklık ve/veya tibial subluksasyon, uygun femoral ve tibial rezeksiyon miktar ve açıları ile kemik defektlerinin yönetimi açısından değerlendirilmelidir. Lateral radyografide posterior osteofit varlığı araştırılmalı, daha iyi eklem hareket açıklığı ve optimum yumuşak doku dengesi için ameliyat sırasında osteofitler çıkarılmalıdır. ${ }^{[4]}$

\section{CERRAHI YAKLAŞIM}

Hem varus hem de valgus dizler için TDP'de medial parapatellar yaklaşım standart yaklaşımdır ve çoğu cerrah bu tekniği tercih eder. ${ }^{[4]}$ Daha fazla deneyimin olması, daha kolay patella eversiyonu ile osteotomi gerektirmeden iyi bir ekspojur (görüntüleme) sağlaması medial yaklaşımın avantajları arasında yer alır. Diğer taraftan, medial yaklaşım orta ve ileri evre valgus diz artrozunda posterolateral köşeye erişimde zorluğa ve kontrakte yumuşak dokuların serbestleştirilmesi için yapılan lateral gevşetme sırasında patellanın damarsal yapısında bozulmaya neden olabilir. ${ }^{[4,14]}$ Ayrıca, medial yaklaşım, medial yumuşak dokuların istemsiz aşırı gevşetilmesiyle instabilite için daha yüksek risk potansiyeline sahiptir. Lateral parapatellar yaklaşım ise valgus dizler için Avrupa ülkelerinde daha çok tercih edilmektedir. Medial yapıların ve patellar kan akımının korunması, optimize edilmiş patellar kayma (tracking) ve daha az ekspojur ile lateraldeki kontrakte yumuşak dokuların serbestleştirilmesi için doğrudan erişim sağlaması ve daha az kısıtlı implant ihtiyacı olasılığı ile geleneksel medial parapatellar yaklaşıma bir alternatiftir. [5,15,16] Ancak lateral yaklaşım daha az deneyimle, yeterli bir ekspojur sağlamak için olası bir tibial tüberkül 


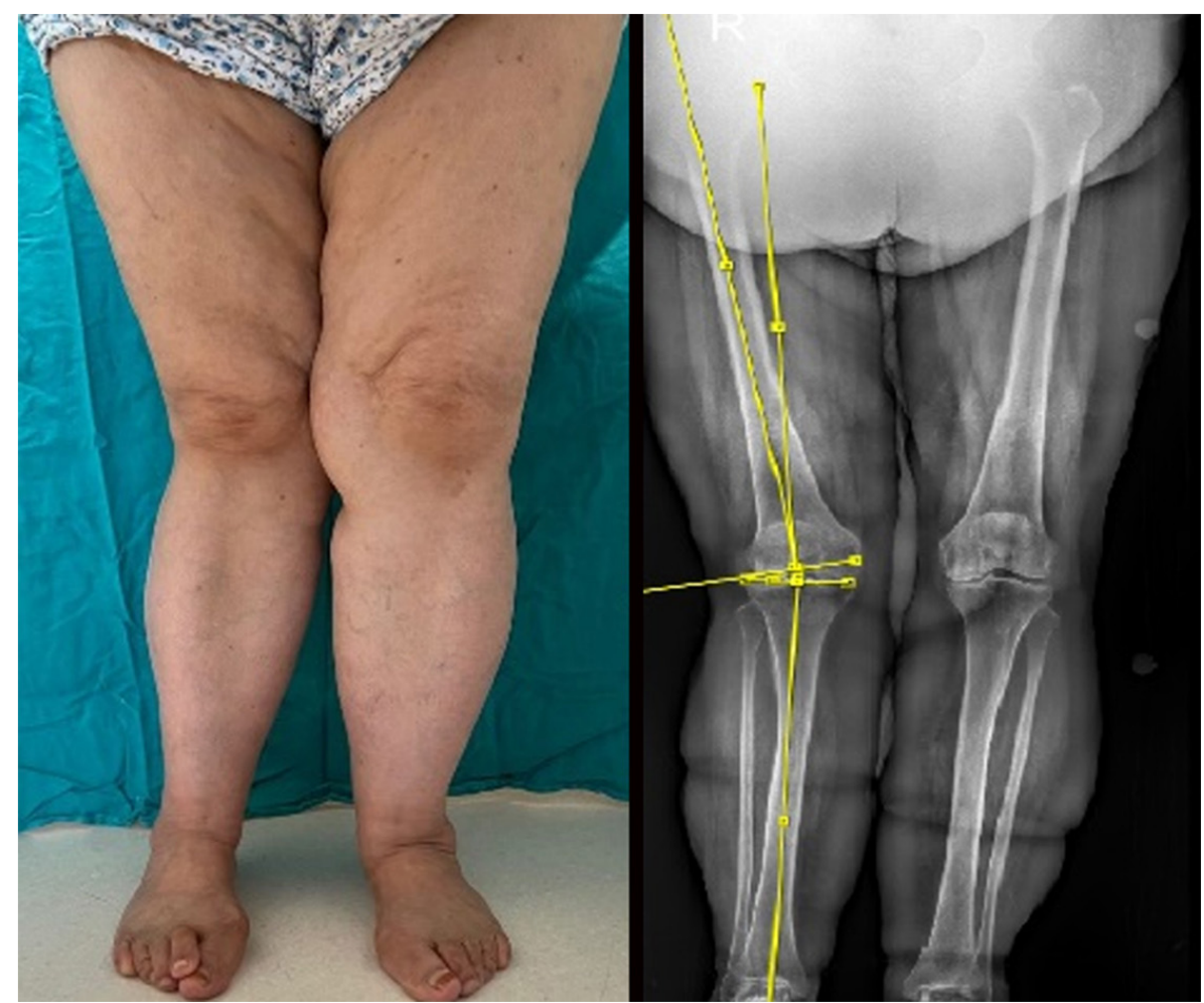

Şekil 3. Ameliyat öncesi klinik görünüm ve yük vererek çekilen bacak uzunluk grafisi.

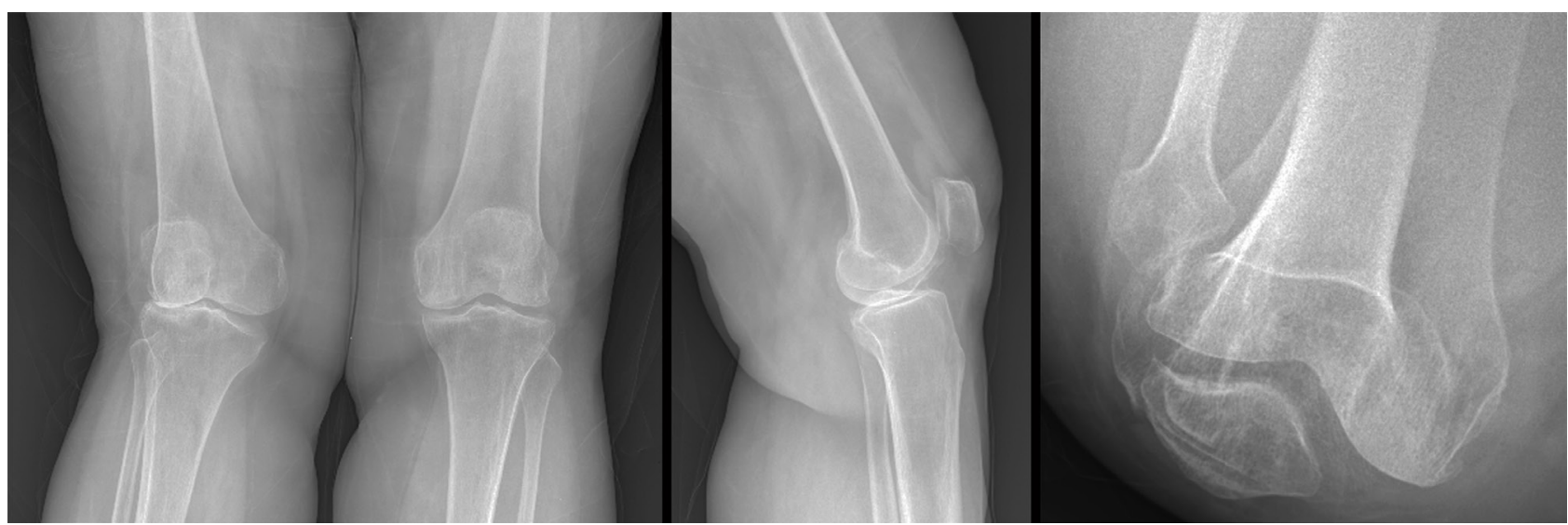

Şekil 4. Ameliyat öncesi yük vererek çekilen ön-arka ve yan grafiler ile Merchant grafisi.

osteotomisi veya kuadriseps snip ihtiyacı ve dizilim restorasyonu sonrasında yumuşak doku kapanmasında sorun gibi olası teknik zorluklar ve nörovasküler komplikasyonlarla daha fazla ilişkilendirilebilir. ${ }^{[4,7]}$

\section{Mekanik Dizilim ve Kemik Rezeksiyonu}

Bağ dengesinin sağlandı̆̆ı, kemik kesilerin mekanik eksene dik yapıldığı, koronal planda nötral dizilimli alt ekstremiteye ve optimum $Q$ açısına sahip stabil bir diz, başarılı klinik sonuçlar ve implant sağkalımı için önemli olduğundan, TDP'nin birincil hedefleri arasında yer alır. ${ }^{[4,17,18]}$ Kemik kesilerinin uygun olmadığı ve nötral mekanik aksın sağlanamadığı bir TDP düşük memnuniyet düzeyi, patellofemoral sorunlar, erken implant yetmezliği ve artmış komplikasyon oranlarını beraberinde getirecektir. ${ }^{[17,19,20]}$ Nötral dizilimli erişkin dizinde tipik olarak ortalama $6^{\circ}$ valgus açısı mevcuttur. Valgus dizde distal femoral kesinin varus dizlerdeki gibi $6^{\circ}$ valgus 


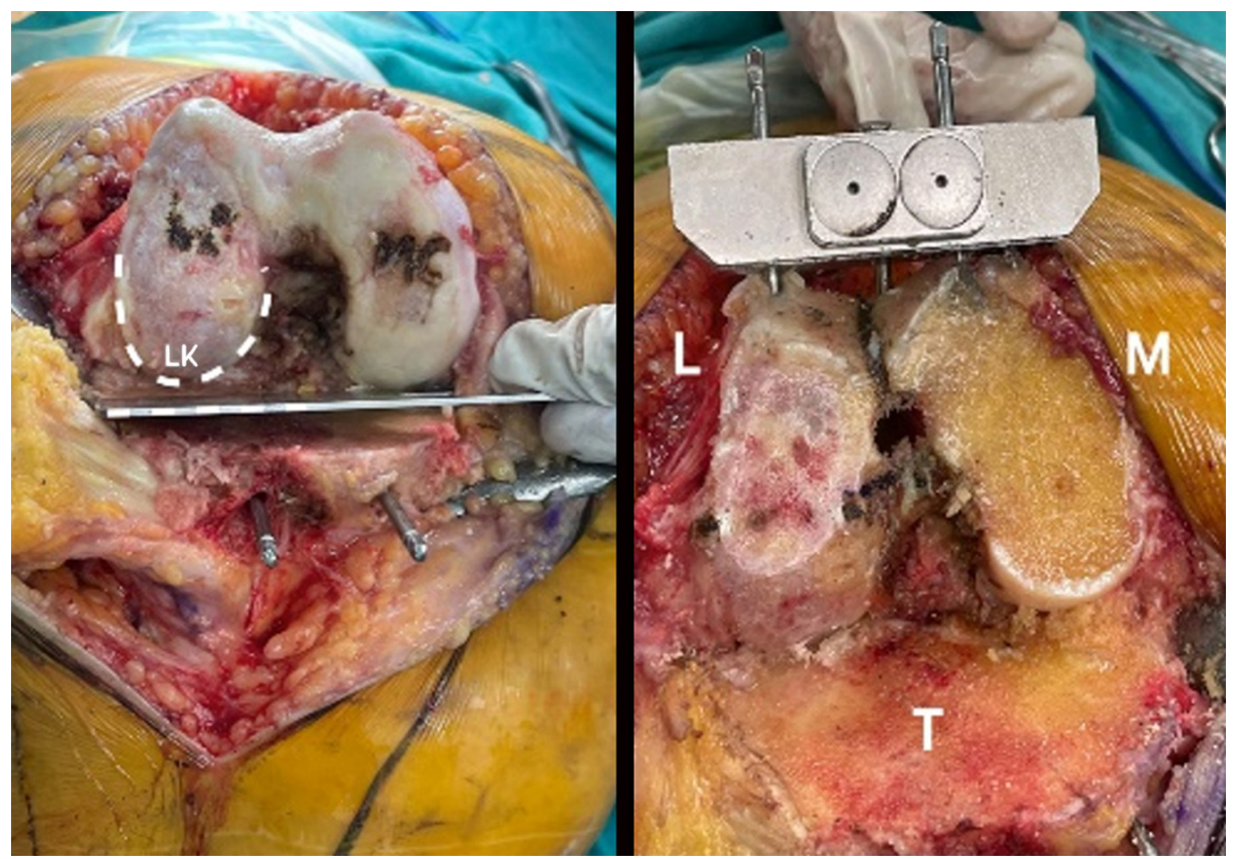

Şekil 5. Atrofik Lateral femoral kondilin distal femoral rezeksiyon (kesi) öncesi ve sonrası görünümü (LK, lateral kondil; L, lateral; M, medial; T, tibia).

açısı hedeflenerek yapılması, rezidüel (kalıcı) valgus yanIış dizilimi ile sonuçlanabilir. ${ }^{[21]} \mathrm{Bu}$ yüzden, valgus diz artroplastisinde distal femoral rezeksiyonun (kesinin) $3^{\circ}$ valgus açısıyla yapılması, bu dizlerde yetersiz düzeltmenin önüne geçecektir. ${ }^{[22,23]}$ Distal femoral kesi lateral kondilde 1-2 mm veya hiç olmazken, medial kondilde 10 mm'yi (genellikle 7-8 mm) geçmemelidir. ${ }^{[24]}$

Valgus dizde sıklıkla görülen lateral femoral kondil atrofisi (Şekil 5) nedeniyle minimum kemik kesisi, eklem çizgisi restorasyonu için önemlidir. ${ }^{[23]}$ Bu dizlerde posterior lateral femoral kondilin genellikle yetersiz oluşu, kemik kesiler için posterior kondiler eksenin referans alınması halinde femoral bileşenin malrotasyonuna (iç rotasyonuna) neden olabilir (Şekil 6). Bunun yerine, önarka (AP) eksen (Whiteside çizgisi), trans-epikondiler eksen ve tibial şaft ekseni, doğru femoral komponent rotasyonunu elde etmek için referans olarak kullanılmalıdır (Şekil 7). ${ }^{[4,17,19]}$ Ayrıca troklear displazinin eşlik ettiği ciddi valgus deformiteli dizlerde Whiteside çizgisini belirlemek zor olacağından, kemik kesilere önce tibiadan başlamak ve tibial kesiye paralel olarak ölçüm yöntemiyle distal femoral kesi yapmak, femoral bileşendeki rotasyon kusuru ihtimalini azaltabilir. ${ }^{[24]}$

Tibial kemik rezeksiyonu ise, tibianın mekanik eksenine dik olmalıdır. Tibial kesiler yapılmadan önce tüm osteofitlerin uzaklaştırıldığından emin olunmalı ve medial tibial platodan $6-8 \mathrm{~mm}$ kesi yapılmalıdır. Tibial kesi hizalama kılavuzu ile dizilim doğrulandıktan

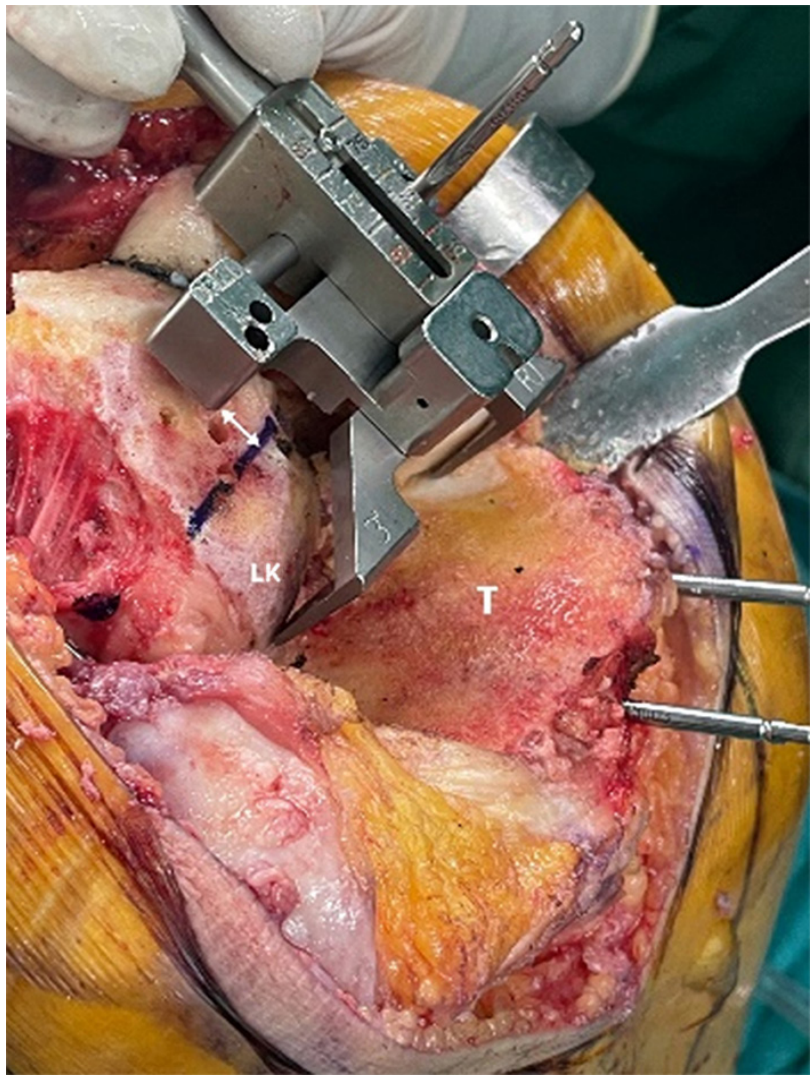

Şekil 6. Valgus dizde posterior kondiler eksenin referans alınarak yapılacağı femoral keside, kesi kılavuzunun istenmeyen iç rotasyonu (LK, lateral kondil; T, tibia). 


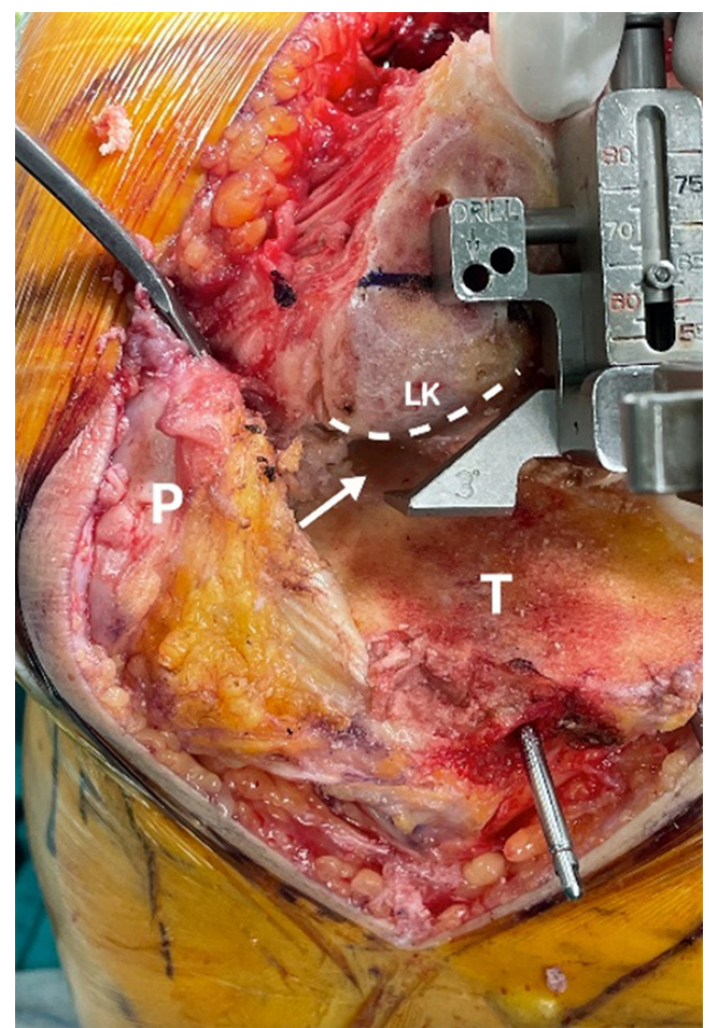

Şekil 7. Valgus dizde doğru femoral komponent rotasyonunu elde etmek için posterior kondiler eksen yerine Whiteside çizgisi ve transepikondiler hattın referans olarak kullanılması (P, patella; $\mathrm{T}$, tibia; LK, lateral kondil).

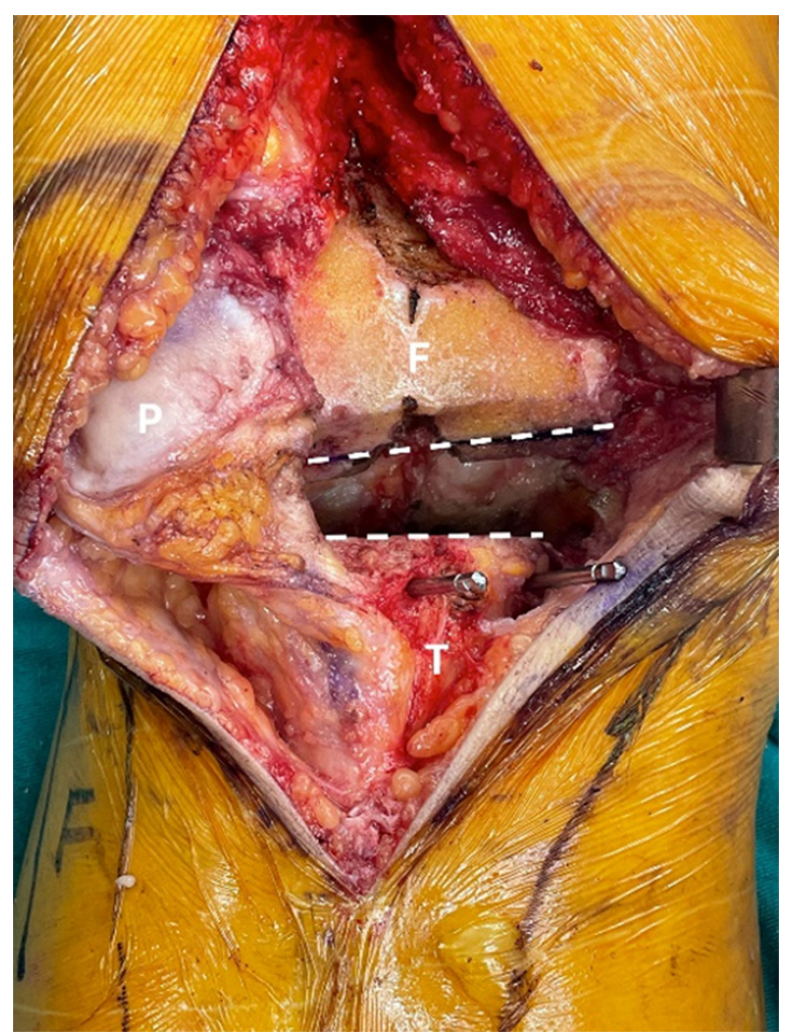

Şekil 8. Kemik kesileri sonrası simetrik olmayan ekstansiyon aralığı mevcudiyetinde lateral yapıların gevşetilmesi gereklidir ( $P$, patella; $F$, femur; $T$, tibia). sonra yapılmalıdır. Zira, yalnızca proksimal tibial anatomi esas alınarak yapılacak tibial kesi, fark edilmemiş ekstra-artiküler tibial valgus varlığında, deformitenin eksik düzeltilmesine yol açabilir. ${ }^{[25]}$

\section{Yumuşak Doku Prosedürü}

Yumuşak doku dengesi, valgus diz artroplastisinin en zorlu yönü olup, literatürde gevşetilmesi gereken yapılar ve gevşetme sırası konusunda halen fikir birliği sağlanamamıştır. ${ }^{[4]}$ Yumuşak dokuları dengelemek ve ideal patellofemoral dizilimi elde etmek için son 30 yılda birçok cerrahi teknik tanımlanmıştır. ${ }^{[8]}$

İlk olarak Insall ve ark., 31 sabit valgus deformiteli dize uyguladıkları iliotibial bant (ITB), lateral kapsül, DYB, POP ve posterior kapsül gevşetmesinde yüksek oranda geç başlangıçı instabilite tanımladı..26] Whiteside, açıları $12^{\circ}-45^{\circ}$ arasında 231 valgus dizde geç instabiliteden kaçınmak için hem fleksiyon hem de ekstansiyon sıkılığında selektif olarak DYB ve POP, sadece ekstansiyonda sıkılıkta iTB gevşetme (Şekil 8), lateral doku gerginliğinin halen devam ettiği olgularda ise posterior kapsül gevşetme sırasını uygulayarak iyi klinik sonuç bildirdi. ${ }^{[27]}$ Ranawat ve ark., kemik kesileri sonrası dikdörtgen bir boşluk elde etmek için öncelikle ekstansiyonda başladıkları 'içten dışa' basamaklı yumuşak doku gevşetme tekniğini tanımladı. Bu teknikte, sırasıyla marjinal osteofitler uzaklaştırıldı, AÇB ve PLK elektrokoter yardımıyla proksimal tibia boyunca gevşetildi (Şekil 9). Popliteus tendonunu korurken gerektiğinde ITB ve DYB'yi serbestleştirmek için no. 15 cerrahi bistüri ucu ile birden fazla "içten dışa" bıçak insizyonu (pie-crusting) tekniğini uyguladı.[13] Whiteside, valgus dizlerin tümü için standart sıralı bir lateral gevşetmenin mümkün olmadığını belirtti ve lateraldeki yapıların femur epikondillerine yakınlığını esas olarak geliştirdiği gevşetme sırasında, hem fleksiyonda hem de ekstansiyonda gergin olan dizlerde DYB ve POP'un serbestleştirildiği; sadece ekstansiyonda gergin olanlar için ITB ve PLK'nın serbestleştirildiği algoritmayı tanımladı. ${ }^{27]}$ Krackow ve ark., önce iTB'nin ve DYB'nin subperiosteal teknikle ekstansiyonda serbestleştirilmesini, ardından popliteus tendonunun ve posterolateral kapsülün gevşetilmesini, GLB'nin ise yalnızca fleksiyon kontraktürü varlığında eklenmesini önerdiler. ${ }^{[11]}$ Boettner, yemek kitabı 'cook-book' adını verdiği standart yumuşak doku gevşetme tekniğinde, $25^{\circ}$ 'ye kadar valgusu olan 


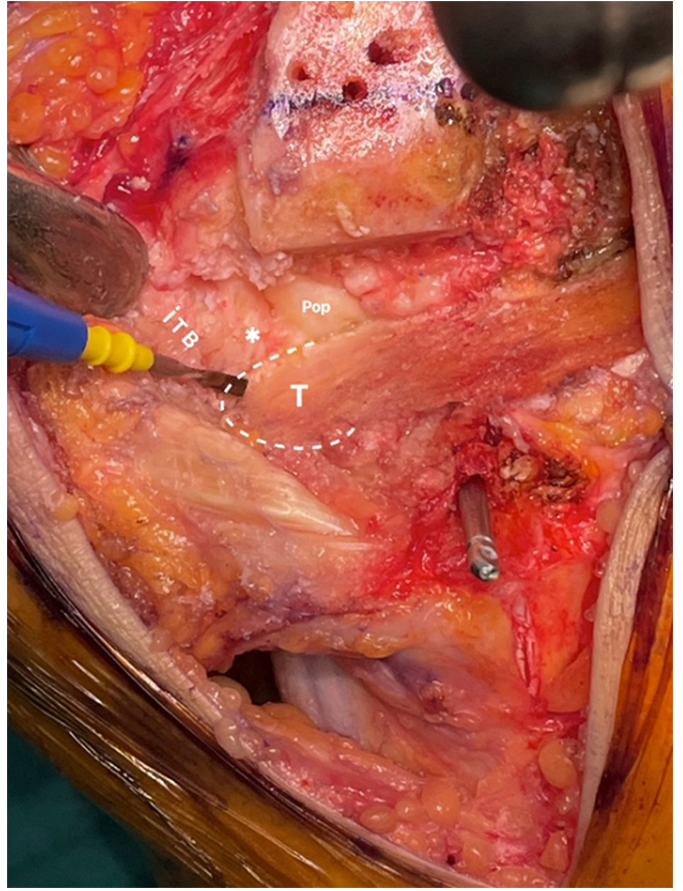

Şekil 9. Ranawat'ın içten-dışa lateral gevşetme tekniğinde tibial kesi yüzeyinin komşuğulundan posterolateral kapsülün elektrokoter yardımıyla serbestleştirilmesi ( $T$, tibia; iTB, iliotibial bant; Pop, popliteus; * posterolateral kapsül).

181 dize rutin ITB ve PLK gevşetme uyguladı ve en az 2 yıllık takipte mükemmel klinik sonuç bildirdi. Yazarlar, olguların yalnızca \%1,1'inde instabilite nedenli revizyon not etse de, olguların \%20,4'ünde kısıtlı implant kullanılmıştı. ${ }^{[8]}$ Mayer ve ark. 42 hastalık serilerinde, sadece PLK gevşetme ile yumuşak doku dengesinin elde edilebildiğini, ek gevşetme gereksinimi olmadığını rapor etti. ${ }^{[28]}$

Ciddi medial gevşeklik durumunda, kısıtlı implantın kullanıl (a) madığı olgularda medial ilerletme teknikleri de önerilmiştir. ${ }^{[29]}$ Krackow, iYB'nin fonksiyonel olmadığı ya da rezidüel medial laksitenin bulunduğu evre 2 valgus dizlerde, özellikle bağ koruyan bir protez tercih edilmişse, medial yapıların kendi üzerine dikilerek (Şekil 10), u çivisi veya vida tespiti ile gerilmesini, ya da IYB'nin tibial yapışma yerinden kaldırılarak distale ilerletilmesini önermiştir. Benzer şekilde, Mou ve ark. medial femoral epikondilin yukarı kaydırma osteotomisi ile IYB germe tekniği tanımlamıştır. ${ }^{[11,30]}$ Medial germe/ilerletme teknikleri komplikasyona açık olup, cerrahi deneyim gerektirmektedir.

\section{İmplant Seçimi}

Valgus diz artroplastisinde kullanılması gereken implant kısıtlamasının derecesi konusunda bir fikir birliği

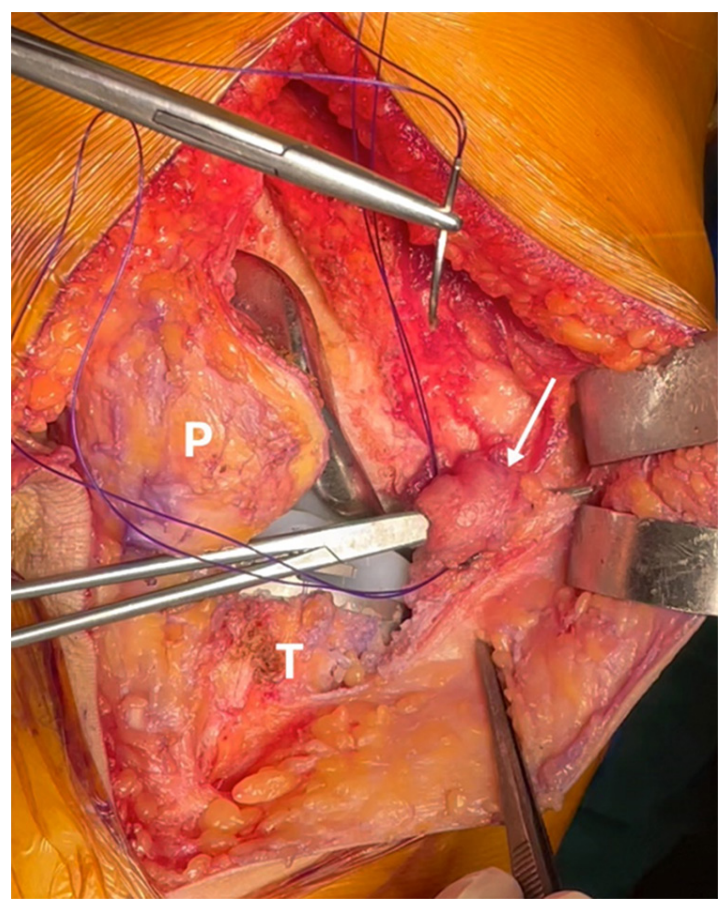

Şekil 10. İmplantasyon sonrası rezidüel gevşekliğin giderilmesi için iYB'nin kendi üzerinde katlanarak gerilmesi tekniği ( $T$, tibia; $P$, patella).

yoktur. ${ }^{[4]}$ Valgus deformitesinde AÇB sıklıkla kontraktedir ve intakt bırakılması deformiteyi düzeltmeyi zorlaştırabilir. ${ }^{[31]}$ Ayrıca, post-cam mekanizması sayesinde bağ kesen (PS) tasarımların (Şekil 11) valgus dizlerde bağ koruyanlara (CR) göre daha stabil olduğu, daha iyi femoral lateralizasyonla daha uyumlu patellofemoral hareket sağladığı ve lateral retinaküler gevşetme ihtiyacını azalttı̆̆ı gösterilmiştir. ${ }^{[13]}$ Eşlik eden pes planovalgus varlığında CR implant uygulanan dizlerde başarısızlık bildirildiğinden, valgus diz deformiteli hastalar ipsilateral tibialis posterior tendon yetmezliği varlığı açısından mutlaka incelenmelidir. ${ }^{[24]}$ Ranawat'a göre, evre I ve II valgus dizlerde posteriordan stabilize edici TDP'ler yeterli olabilirken; ileri evre valgus dizde kısıtlayıcı protezlerin ya da menteşeli tasarım gereksinimi mevcuttur. ${ }^{[8,10,13]}$ Kısıtlayıcılık düzeyinin ana belirleyicisi deformitenin sabit veya stres testleriyle düzeltilebilir oluşudur. Sabit bir valgus deformitesinde, lateral gevşetme sonrası hem medial hem de lateral yapıların fonksiyonelliği ortadan kalkacağından, diz 'instabil' kabul edilerek yarı kısıtlayıcı implant kullanımı gerekebilir. ${ }^{[24]}$ Pang ve ark. evre 2 valgus dizlerde kısıtlayıcı implantlar ile PS veya CR tasarımını karşılaştırdıkları çalışmalarında, gruplar arasında ön-arka veya mediolateral stabilite açısından fark bulunmadığını, ancak 


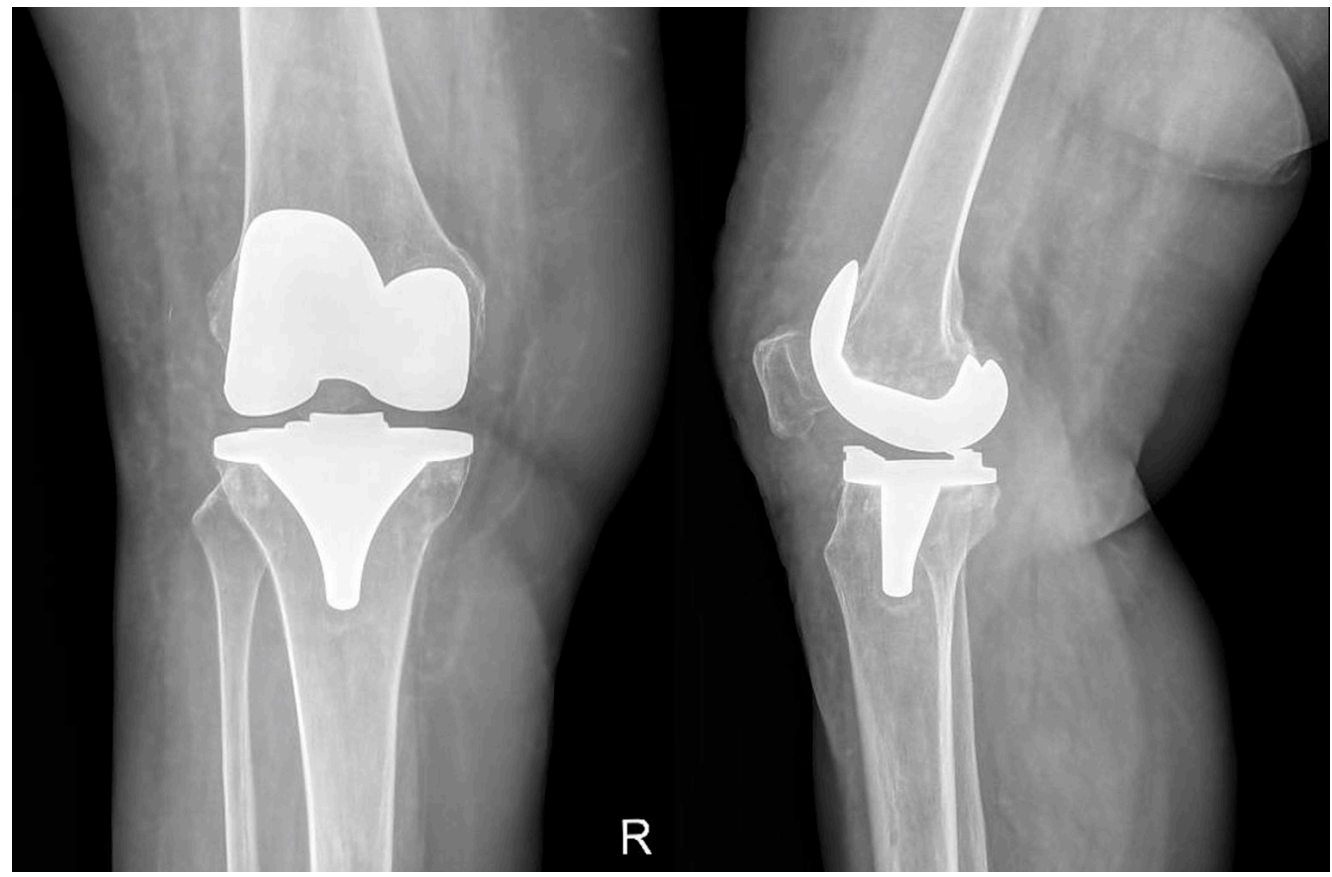

Şekil 11. Bağ kesen TDP ve IYB germe yapılan valgus dizin ameliyat sonrası ön-arka ve yan grafileri.

kısıtlayıcı tasarımlarda daha fazla eklem seviyesi değişimi olduğunu gözlemlemişlerdir. ${ }^{[32]}$ Diğer taraftan, medial yapıların kesinlikle işlevsiz olduğu, kemik deformitesinin $20^{\circ}$ 'nin üzerinde ve sabit olduğu evre 3 valgus dizde stabilite için kısıtlayıcı implant kullanımı zorunludur. ${ }^{[24,32]}$

\section{KOMPLIKASYONLAR}

TDP uygulanan ağrılı valgus artritik dizli hastalardaki komplikasyonlar; tekrarlayan valgus deformitesi (\%4-38), tibiofemoral instabilite (\%2-70), yara sorunları (\%4-13), ameliyat sonrası manipülasyon gerektiren EHA kısıtlılı̆̆ı (\%1-20), patellar tracking sorunları (\%2- \%10), patellada stres kırığı veya osteonekroz (\%1-12) ve peroneal sinir arazı (\%1-4) olarak sıralanabilir. ${ }^{[3]}$ Peroneal sinir arazı olası en ciddi komplikasyondur. Deformite düzeltilmesini takiben dolaylı olarak traksiyon ve/veya iskemiye bağlı hasar gelişebildiği gibi, Ranawat'ın tanımladığı içten dışa gevşetme cerrahi tekniğinde tibial kesi seviyesinde PLK gevşetme sırasında doğrudan sinir hasarı meydana gelebilir. ${ }^{[34]}$ Ameliyat sonrası erken dönemde dizin hafif fleksiyonda tutulması bu komplikasyonun önlenmesine yardımcı olabilir. ${ }^{[1,4]}$ illeri evre valgus dizlerde cerrahi prosedüre peroneal sinir gevşetmesinin eklenmesi bu yıkıcı komplikasyonun azaltılmasına yardımcı olabilir. ${ }^{[1,4]}$

\section{SONUÇ}

Ağrılı artritik valgus diz deformitesi, klasik bir varus dizinin ayna görüntüsü olmayıp, günümüzde bu dizlerin protez cerrahisinde halen kendine özgü zorlukları bulunmaktadır. Yumuşak dokusu dengeli ve nötral mekanik aksa sahip, stabil ve fonksiyonel bir eklem elde etmek için birçok gevşetme prosedürü ve farklı implant tasarımları kullanılmaktadır. Anahtar rolü üstlenen yumuşak doku dengesini sağlamada fikir birliği sağlanamamışken, her hasta için standart gevşetme prosedürü yerine, simetrik aralıklar elde etmek üzere aşamalı gevşetme ve mümkün olan en az kısıtlı implant tasarımının tercih edilmesi önerilmektedir.

\section{KAYNAKLAR}

1. $\mathrm{XuJ}$ J, Liu H, Luo F, Lin Y. Common peroneal nerve 'pre-release' in total knee arthroplasty for severe valgus deformities. Knee 2020;27(3):980-86. Crossref

2. Cheng $X$, Wang Z, Zhang $Y$, Wang $M$, Zhang $X$. Tightening medial collateral ligament during total knee arthroplasty for patients with fixed valgus deformity: A novel technique. J Orthop Surg (Hong Kong) 2019;27(1):2309499019834695. Crossref

3. Zhou X, Wang M, Liu C, Zhang L, Zhou Y. Total knee arthroplasty for severe valgus knee deformity. Chin Med J (Engl) 2014;127(6):1062-6. https://pubmed.ncbi.nlm.nih. gov/24622435 
4. Alesi D, Meena A, Fratini S, Rinaldi VG, Cammisa E, Lullini G, Vaccari V, Zaffagnini S, Marcheggiani Muccioli GM. Total knee arthroplasty in valgus knee deformity: is it still a challenge in 2021? Musculoskelet Surg 2021. Crossref

5. Li F, Liu N, Li Z, Wood KB, Tian H. Lateral femoral sliding osteotomy in total knee arthroplasty with valgus deformity greater than twenty degrees. Int Orthop 2019;43(11):25117. Crossref

6. Kawaguchi K, Inui H, Taketomi S, Yamagami R, Takagi K, Kage T, Sameshima S, Tanaka S. Rotational kinematics differ between mild and severe valgus knees in total knee arthroplasty. Knee 2021;28:81-8. Crossref

7. Wang B, Xing D, Li JJ, Zhu Y, Dong S, Zhao B. Lateral or medial approach for valgus knee in total knee arthroplasty - which one is better? A systematic review. J Int Med Res 2019;47(11):5400-13. Crossref

8. Boettner F, Renner L, Narbarte DA, Egidy C, Faschingbauer M. Total knee arthroplasty for valgus osteoarthritis: the results of a standardized soft-tissue release technique. Knee Surg Sports Traumatol Arthrosc 2016;24(8):2525-31. Crossref

9. Cheng W, Li Z, Zhang J, Cao Q, Yu H, Qi L, Yao F, Jing J. A lateral parapatellar approach with iliotibial band dissection from the Gerdy tubercle for total knee arthroplasty of the valgus knee. Exp Ther Med 2021;21(1):38. Crossref

10. Apostolopoulos AP, Nikolopoulos DD, Polyzois I, Nakos A, Liarokapis S, Stefanakis G, Michos IV. Total knee arthroplasty in severe valgus deformity: interest of combining a lateral approach with a tibial tubercle osteotomy. Orthop Traumatol Surg Res 2010;96(7):777-84. Crossref

11. Krackow KA, Jones MM, Teeny SM, Hungerford DS. Primary total knee arthroplasty in patients with fixed valgus deformity. Clin Orthop Relat Res 1991;(273):9-18. Crossref

12. Vedoya S. A new classification for the valgus knee related to total knee arthroplasty and implant selection. J Orthop Trauma Surg Rel Res 2020;15(3):33-7. https://www.jotsrr. org/articles/a-new-classification-for-the-valgus-knee-relatedto-total-knee-arthroplasty-and-implant-selection.pdf

13. Ranawat AS, Ranawat CS, Elkus M, Rasquinha VJ, Rossi $\mathrm{R}$, Babhulkar S. Total knee arthroplasty for severe valgus deformity. J Bone Joint Surg Am 2005;87(1):271-84. Crossref

14. Rawal J, Devany AJ, Jeffery JA. Arthroplasty in the Valgus Knee: Comparison and Discussion of Lateral vs Medial Parapatellar Approaches and Implant Selection. Open Orthop J 2015;15;9(1):94-7. Crossref

15. Li H, Ponzio DY, Ong A, Wei W, Wang B, Li Z, Zhou D. Total Knee Arthroplasty for Fixed Valgus Deformity Correction Using a Modified Lateral Parapatellar Approach. J Knee Surg 2020;33(4):372-7. [Erratum in: J Knee Surg 2020;33(4):e2. https://doi.org/10.1055/s-0039-3399509] Crossref

16. Greenberg A, Kandel L, Liebergall M, Mattan Y, Rivkin G. Total Knee Arthroplasty for Valgus Deformity via a Lateral Approach: Clinical Results, Comparison to Medial Approach, and Review of Recent Literature. J Arthroplasty 2020;35(8):2076-83. Crossref

17. Rivière C, Iranpour F, Auvinet E, Howell S, Vendittoli PA, Cobb J, Parratte S. Alignment options for total knee arthroplasty: A systematic review. Orthop Traumatol Surg Res 2017;103(7):1047-56. Crossref

18. Gao F, Ma J, Sun W, Guo W, Li Z, Wang W. Radiographic assessment of knee-ankle alignment after total knee arthroplasty for varus and valgus knee osteoarthritis. Knee 2017;24(1):107-15. Crossref
19. Xie K, Lyons ST. Soft Tissue Releases in Total Knee Arthroplasty for Valgus Deformities. J Arthroplasty 2017;32(6):1814-8. Crossref

20. Chou W-Y, Siu K-K, Ko J-Y, Chen J-M, Wang C-J, Wang F-S, Wong T. Preoperative templating and computer-assisted total knee arthroplasty for arthritic valgus knee. J Arthroplasty 2013;28(10):1781-7. Crossref

21. Cherian J, Kapadia $\mathrm{BH}$, Banerjee $\mathrm{S}$, Jauregui JJ, Issa $\mathrm{K}$, Mont MA. Mechanical, anatomical, and kinematic Axis in TKA. concepts and practical applications. Curr Rev Musculoskelet Med 2014;7(2):89-95. Crossref

22. Elkus M, Ranawat CS, Rasquinha VJ, Babhulkar S, Rossi R, Ranawat AS. Total knee arthroplasty for severe valgus deformity. Five to fourteen-year follow-up. J Bone Joint Surg Am 2004;86(12):2671-6. Crossref

23. Lombardi AV Jr, Dodds KL, Berend KR, Mallory TH, Adams JB. An algorithmic approach to total knee arthroplasty in the valgus knee. J Bone Joint Surg Am 2004;86(Suppl 2):62-71. Crossref

24. Rossi R, Rosso F, Cottino U, Dettoni F, Bonasia DE, Bruzzone M. Total knee arthroplasty in the valgus knee. Int Orthop 2014;38(2):273-83. Crossref

25. Alghamdi A, Rahmé M, Lavigne M, Massé V, Vendittoli PA. Tibia valga morphology in osteoarthritic knees: importance of preoperative full limb radiographs in total knee arthroplasty. J Arthroplasty 2014;29(8):1671-6. Crossref

26. Insall JN, Easley ME. Surgical Techniques and instrumentation in total knee arthroplasty. In: Insall JN, Scott WN, editors. Surgery of the Knee, 3rd ed., Vol 2. New York: Churchill Livingstone; 2001. p.1553-620.

27. Whiteside LA. Selective ligament release in total knee arthroplasty of the knee in valgus. Clin Orthop Relat Res 1999;367:130-40. Crossref

28. Chechik O, Mayer C, Drexler M, Sternheim A, Snir N, Dekel S. Posterolateral capsular release for correction of valgus deformity. J Knee Surg 2012;25(5):355-60. Crossref

29. Healy WL, lorio R, Lemos DW. Medial reconstruction during total knee arthroplasty for severe valgus deformity. Clin Orthop Relat Res 1998;356:161-9. Crossref

30. Mou P, Zeng Y, Yang J, Zhong H, Yin S-J, Li R-B. The effectiveness of medial femoral epicondyle up-sliding osteotomy to correct severe valgus deformity in primary total knee arthroplasty. J Arthroplasty 2018;33(9):2868-74. Crossref

31. Mihalko WM, Krackow KA. Anatomic and biomechanical aspects of pie crusting posterolateral structures for valgus deformity correction in total knee arthroplasty: a cadaveric study. J Arthroplasty 2000;15(3):347-53. Crossref

32. Pang H-N, Yeo S-J, Chong H-C, Chin P-L, Chia S-L, Lo $\mathrm{N}-\mathrm{N}$. Joint line changes and outcomes in constrained versus unconstrained total knee arthroplasty for the type II valgus knee. Knee Surg Sports Traumatol Arthrosc 2013;21(10):2363-9. Crossref

33. Favorito PJ, Mihalko WM, Krackow KA. Total knee arthroplasty in the valgus knee. J Am Acad Orthop Surg 2002;10(1):16-24. Crossref

34. Bruzzone M, Ranawat A, Castoldi F, Dettoni F, Rossi P, Rossi $\mathrm{R}$. The risk of direct peroneal nerve injury using the Ranawat "inside-out" lateral release technique in valgus total knee arthroplasty. J Arthroplasty 2010;25(1):161-5. Crossref 